\title{
Cognitive Rehabilitation Interventions for Neglect and Related Disorders: Moving from Bench to Bedside in Stroke Patients
}

\section{Citation}

Barrett, Anna M., Laurel J. Buxbaum, H. Branch Coslett, Emmeline Edwards, Kenneth M. Heilman, Argye E. Hillis, William P. Milberg, and lan H. Robertson. 2006. “Cognitive Rehabilitation Interventions for Neglect and Related Disorders: Moving from Bench to Bedside in Stroke Patients." Journal of Cognitive Neuroscience 18 (7): 1223-36. doi:10.1162/ jocn.2006.18.7.1223.

\section{Permanent link}

http://nrs.harvard.edu/urn-3:HUL.InstRepos:41543029

\section{Terms of Use}

This article was downloaded from Harvard University's DASH repository, and is made available under the terms and conditions applicable to Other Posted Material, as set forth at http:// nrs.harvard.edu/urn-3:HUL.InstRepos:dash.current.terms-of-use\#LAA

\section{Share Your Story}

The Harvard community has made this article openly available.

Please share how this access benefits you. Submit a story.

\section{Accessibility}




\title{
Cognitive Rehabilitation Interventions for Neglect and Related Disorders: Moving from Bench to Bedside in Stroke Patients
}

\author{
Anna M. Barrett ${ }^{1 *}$, Laurel J. Buxbaum ${ }^{2}$, H. Branch Coslett ${ }^{3}$, \\ Emmeline Edwards ${ }^{4}$, Kenneth M. Heilman ${ }^{5}$, Argye E. Hillis ${ }^{6}$, \\ William P. Milberg ${ }^{7}$, and Ian H. Robertson ${ }^{8}$
}

\begin{abstract}
The spatial neglect syndrome, defined by asymmetric attention and action not attributed to primary motor or sensory dysfunction and accompanied by functional disability, is a major cause of post-stroke morbidity. In this review, we consider the challenges and obstacles facing scientific researches wishing to evaluate the mechanisms and effectiveness of rehabilitation interventions. Spatial neglect is a heterogeneous disorder, for which consensus research defi-
\end{abstract}

\section{INTRODUCTION}

In the cognitive rehabilitation field, there is a pressing need for a paradigm shift from diagnosis and descriptive analysis of neuropsychological impairments to systematic linkage of diagnosis with intervention procedures. The National Institute of Neurological Disorders and Stroke (NINDS) has established three research working groups to promote the use of evidence-based interventions in the evaluation, treatment, and assistance of patients with disorders of the brain affecting higher thought processes. These working groups are currently focused on a limited set of neurological conditions where progress in the rehabilitation of higher thought processes would benefit from formal partnerships between basic cognitive neuroscientists and clinicians in assessing residual capacity within specified lesioned circuits and potential for functional return. Stroke, brain tumor, and traumatic brain injury were identified as conditions where such

\footnotetext{
*Authors are listed in alphabetical order

${ }^{1}$ Kessler Medical Rehabilitation Research and Education Corporation, West Orange, NJ, ${ }^{2}$ Moss Rehabilitation Research Institute, Philadelphia, PA, ${ }^{3}$ University of Pennsylvania School of Medicine, Philadelphia, ${ }^{4}$ National Institute of Neurological Disorders and Stroke, Bethesda, MD, ${ }^{5}$ University of Florida School of Medicine, Gainesville, ${ }^{6} J o h n s$ Hopkins University School of Medicine, Baltimore, ${ }^{7}$ Harvard Medical School, Boston, ${ }^{8}$ Trinity College, Dublin
}

nitions are not currently available, and it is unclear which of the deficits associated with the syndrome causes subsequent disability. We review current opinion about methods of assessment, suggest a rational approach to selecting therapies which requires further study, and make systems-level and theoretical recommendations for building theory. We lastly review some creative questions for consideration in future research. collaborations would assist in deciding what inputs or interventions need to be maximized to allow restitution.

This article summarizes the discussions and recommendations of the Stroke Rehabilitation Team, a multidisciplinary team of scientists including neurologists, cognitive neuroscientists, psychologists, rehabilitation specialists, and functional imaging experts. Under the leadership of Dr. H. Branch Coslett, the group focused their efforts on the problem of spatial neglect and its related disorders with the primary goal to accelerate progress in the field of cognitive rehabilitation for stroke patients.

\section{NEGLECT AND RELATED DISORDERS: SCOPE OF THE PROBLEM}

The neglect syndrome is a complex disorder of spatial representation, spatiomotor programming, spatial attention, and arousal. The hallmark of the disorder is a failure to report, orient toward, or respond to stimuli in contralesional space, which cannot be attributed to primary motor or sensory dysfunction (Heilman, Watson, \& Valenstein, 1985). Neglect is a common consequence of right-hemisphere stroke. Its reported incidence ranges from 13\% (Stone, Patel, Greenwood, \& Halligan, 1992) to $81 \%$ of patients with right-hemisphere stroke (Sunderland, Wade, \& Langton Hewer, 1987), presumably reflecting differences in subject inclusion criteria, 
lesion location, and assessment procedures (see Bowen, McKenna, \& Tallis, 1999); a number of recent studies indicate that about $50 \%$ of patients exhibit the disorder (Buxbaum, Ferraro, Veramonti, et al., 2004; Mapstone et al., 2003). Neglect may also be observed in patients with left-hemisphere stroke, but it is more common and more severe in association with right-hemisphere lesions (Ringman, Saver, Woolson, Clarke, \& Adams, 2004; Gainotti, 1972). The incidence of neglect may be influenced by age. For example, in one study only 5\% of 18- to 50-year-old patients exhibited neglect 1 week after stroke, whereas 18\% of comparable patients over 80 had neglect (Ringman et al., 2004). The disorder may be observed in children as well as adults (e.g., Laurent-Vannier, Pradat-Diehl, Chevignard, Abada, \& De Agostini, 2003).

The disabilities associated with neglect induce a substantial burden to patients, families, and the entire medical system. The neglect syndrome is associated with severe impairments in a wide range of activities of daily living such as eating, dressing, and walking, thereby limiting independence. The presence of the neglect syndrome has been demonstrated to be a predictor of poor response to rehabilitation (e.g., Cherney, Halper, Kwasnica, Harvey, \& Zhang, 2001) and inadequate functional outcome. Several studies have demonstrated that family burden is greater and functional outcome worse for patients with neglect than would be predicted by severity of sensory-motor deficits or lesion size (Buxbaum, Ferraro, Veramonti, et al., 2004; Paolucci, Antonucci, Grasso, \& Pizzamiglio, 2001; Katz, HartmanMaeir, Ring, \& Soroker, 1999).

This article will briefly review disorders commonly associated with neglect as well as the evidence that they may be important determinants of the severity of associated disability. It will also review current approaches to the assessment and treatment of neglect. Finally, it will discuss approaches to the assessment and treatment of neglect that offer promise.

\section{NEGLECT IS A HETEROGENEOUS DISORDER}

Work in monkeys (Watson, Valenstein, Day, \& Heilman, 1986) and humans (Tegner, \& Levander, 1991; Bisiach, Geminiani, Berti, \& Rusconi, 1990; Coslett, Bowers, Fitzpatrick, Haws, \& Heilman, 1990) suggest that neglect may differentially affect perceptual-attentional and intentional/preparatory functions. Similarly, neglect may differentially affect representations of space as compared to the body (e.g., "personal neglect": Beschin \& Robertson, 1997; Guariglia \& Antonucci, 1992; Bisiach, Perani, Vallar, \& Berti, 1986). Some investigators have found dissociations between neglect of the left side of the viewer (i.e., egocentric neglect) and neglect of the left side of individual stimuli (i.e., object-based neglect: e.g., Hillis \& Caramazza, 1995; Ota, Fujii, Suzuki, Fukatsu, \& Yamadori, 2001). These and other observa- tions (e.g., near vs. far neglect: Ota et al., 2001) have led a number of investigators to propose that there might be several distinct neglect subtypes. Proponents of this view suggest that, for example, some patients show primarily motor-intentional neglect characterized by impairment in initiating or executing movements into or toward the contralesional hemispace. The frequency with which motor-intentional neglect occurs has ranged from $6 \%$ to more than $40 \%$ of patients with neglect, depending upon how deficient motor-intention is defined (Buxbaum, Ferraro, Veramonti, et al., 2004; Adair, $\mathrm{Na}$, Schwartz, \& Heilman, 1998; Na et al., 1998). Other patients with neglect exhibit primarily a perceptualattentional deficit characterized by a failure to generate or maintain an adequate representation of the contralesional hemispace. These putative subtypes are not, of course, mutually exclusive; indeed, many subjects with neglect exhibit evidence of both motor-intentional and perceptual-attentional neglect and may, in addition, exhibit different subtypes of neglect defined by different frames of reference.

Factor analysis has been used in an attempt to characterize the heterogeneity in performance exhibited by patients with neglect. Factor analyses of batteries of paper-and-pencil tasks for neglect have generated conflicting results. Halligan, Marshall, and Wade (1989) concluded that performance variability can be accounted for by one factor, whereas the analysis of Azouvi, Samuel, et al. (2002) yielded two factors. McGlinchey-Berroth et al. (1996) reported a factor analysis of a neglect battery including line bisection, four visual search tasks, three construction tasks, two extinction tasks, and single word reading, administered to 120 patients with righthemisphere infarcts. Seven factors were identified, three of which were related to hemispatial neglect: left attentional processing, line bisection, and word reading. The investigators also noted that the three neglect-related factors could not be distinguished neuroanatomically.

Currently there is no consensus on whether the "subtype" or "factor" model best captures the heterogeneity characterizing the performance of neglect subjects. Harvey, Kramer-McCaffery, Dow, Murphy, and Gilchrist (2002) reported data from subjects with neglect tested on three tasks: the overbead task (Nico, 1996), the pulley test (Bisiach, Geminiani, et al., 1990), and the landmark test (Milner, Brechmann, \& Pagliarini, 1992) known to distinguish between sensory-attentional and motor-intentional neglect; they found that the same patients were not consistently classified with these measures. Furthermore, there is only preliminary evidence, in one case study, that subtype-defined patterns of performance are stable across time (Barrett, Crucian, Schwartz, \& Heilman, 1999).

Despite these concerns, the issue of neglect subtypes may be important, as there is some evidence that patients with different symptom profiles may respond differently to treatments, or that treatments may be 
selective to fractionated behaviors. For example, Barrett, Crucian, Beversdoft, and Heilman (2001) and Barrett, Crucian, Schwartz, et al. (1999) demonstrated in single cases that bromocriptine may strongly influence motorintentional neglect, whereas monocular patching may relatively selectively influence perceptual-attentional bias. Additionally, Adair, Na, Schwartz, and Heilman (2003) administered cold water caloric stimulation to patients with sensory-attentional and motor-intentional neglect. They found a differential effect in that the former group exhibited greater improvement after caloric stimulation.

\section{DEFICITS FREQUENTLY ASSOCIATED WITH NEGLECT}

\section{Sustained Attention and Arousal in Neglect}

There is compelling evidence that neglect is associated with impairments in sustained attention and/or arousal and that this deficit may play an important or, in some patients, even decisive, role in their impairment. The right hemisphere may be crucial for mediating at least some aspects of attention including arousal and sustained attention (Heilman \& Van Den Abell, 1980; Heilman, Schwartz, \& Watson, 1978). Thus, it is perhaps not surprising that several studies have demonstrated that neglect is associated with deficits in sustained attention or processing capacity (Duncan et al., 1999; Coslett \& Heilman, 1989).

Work by Robertson and colleagues demonstrated an interaction between sustained attention and lateralized attention in neglect. Increasing attentional demands exacerbates neglect, and neglect impairs performance on tasks assessing sustained attention. For example, Robertson (1998) investigated the influence of a midline auditory alerting stimulus on subjects with left side spatial neglect, and found that this alerting stimulus reduced inattention because it enhanced arousal. Consistent with this view, Robertson, Manly, et al. (1997) demonstrated that neglect is highly correlated with performance on an auditory attention task without a spatial element; also of interest was the fact that a nonlateralized auditory sustained attention task reliably discriminated between righthemisphere lesion subjects with and without neglect.

As noted by Robertson (2001), the fact that spatial neglect can be substantially altered by manipulations that influence arousal strongly supports the view that decreased sustained attention plays a role in the pathogenesis of neglect. Furthermore, the demonstration that improving sustained attention enhances the performance of patients with neglect may have important implications for the treatment of this disorder.

\section{Motor and Sensory Impairments}

Patients with neglect have more motor and sensory impairments than patients without neglect, suggest- ing that primary sensory and motor deficits may be augmented (or perhaps mimicked) by left neglect (Buxbaum, Ferraro, Veramonti, et al., 2004; Barrett, Peterlin, \& Heilman, 2003; Sterzi et al., 1993). For example, tactile sensory deficits in neglect patients may be modified by the position of the arm, such that detection of tactile stimuli is improved by crossing the contralesional limb into the "good" ipsilesional hemispace (Valenza, Seghier, Schwartz, Lazeyras, \& Vuilleumier, 2004; Vallar, 1997; Smania \& Aglioti, 1995). This indicates that at least a portion of the apparent sensory loss is, in actuality, related to a spatial deficit. Additionally, neglect is frequently associated with impaired vision in the contralateral hemispatial field, a pseudohemianopia, but this hemianopia is induced by inattention rather than hemianopia (Muller-Oehring et al., 2003; Nadeau \& Heilman, 1991). Consistent with this view, a recent study of 44 subjects with right-hemisphere stroke found only one patient with visual field defects in the absence of neglect; the correlation of neglect and field deficits was highly significant $(p<.0001)$ (Cassidy, Bruce, Lewis, \& Gray, 1999). Finally, neglect may also be associated with a greater motor deficit that one would expect on the basis of lesion volume alone, implying that neglect may augment primary motor dysfunction (Buxbaum, Ferraro, Veramonti, et al., 2004).

\section{Emotional Dysregulation}

Although it may appear that spatial cognition and emotional processing are entirely different behavioral domains, disorders of emotional processing often coexist with the neglect syndrome. We suggest that altered emotional processing and regulation are a source of disability and may strongly influence the success of treatments for neglect for several reasons. First, disturbances in processing and regulation of affect and motivation interfere with patients' ability to engage in therapy. Second, although few empirical data are available, substantial anecdotal evidence suggests that emotional cognitive disorders undermine the efforts of clinicians and caregivers; clinicians commonly observe that patients with a large right-hemisphere stroke, neglect, and hemiplegia discontinue rehabilitation after a brief period because they do not appear to be "interested" in therapy. Finally, there is widespread agreement among clinicians that patients who lack motivation make few or no therapeutic gains.

\section{Anosognosia and Anosodiaphoria}

Anosognosia refers to an unawareness of illness or deficit (Marcel, Tegner, \& Nimmo-Smith, 2004; Babinski, 1914); anosodiaphoria, in contrast, refers to an indifference to illness or disability (Critchley, 1957). Both are more frequent after right frontal than left-hemisphere lesions (see also Ito et al., 2003; Stone, Halligan, \& 
Greenwood, 1993) and are frequently observed in patients with neglect. Anosognosia may compound the disability from the neglect itself (Adair, $\mathrm{Na}$, Schwartz, Fennell, et al., 1995); lack of awareness of deficits or anosognosia for symptoms such as hemiplegia is an important predictor of poor outcome in rehabilitation. The presence of anosognosia may in part underlie the failure of treatments employing top-down or strategic interventions. Subjects are not likely to implement a strategy for a condition about which they are unaware or indifferent. Although anosognosia often resolves in days to weeks after stroke, anosodiaphoria often persists.

\section{DIAGNOSIS AND ASSESSMENT}

\section{Current Approaches}

Clinical testing for the presence of neglect has focused on assessment of spatial bias in visuomotor tasks. Most of these are "paper-and-pencil" tests performed in peripersonal space. The most commonly used of these tests involve line bisection, copying figures (e.g., copying a scene of a house, fence, and two trees: Ogden, 1985), and visual search tasks in which subjects are asked to "cancel" lines (Albert, 1973), bells (Gauthier, Dehaut, \& Joanette, 1989), or stars (Wilson, Cockburn, \& Halligan, 1987), or locate target letters in rows of random letters. Other visuomotor tests in near-peripersonal space include the Baking Tray Test (Tham \& Tegner, 1996) and writing (often scored on the basis of the width of the left margin). Some tests for neglect reduce motor demands; these include the Landmark Test in which patients are shown prebisected lines (Milner et al., 1992), tests of reading (typically scored on the basis of omissions of words on the side contralateral to the lesion (e.g., Bachman, Fein, Davenport, \& Price, 1993; Caplan, 1987), and the Overlapping Figures Test (Gainotti, D'Erme, \& Bartolomeo, 1991).

The sensitivity of these tests for neglect is extraordinarily variable, with reported ranges from 19\% to 51\% (Azouvi, Samuel, et al., 2002), 37\% to 100\% (Halligan, Marshall, et al., 1989), and 13\% to 82\% (Bowen, McKenna, et al., 1999). This variability may be attributable to a number of factors. As there is no "gold standard" for what constitutes neglect, different investigators adopt different methods for operationally defining neglect. For example, a right-sided starting point on the Bells Test identified more cases than the left minus right omissions on the same test, which in turn identified more cases than using a cutoff score for total omissions on this test (Azouvi, Samuel, et al., 2002). The "incidence" of neglect will thus be substantially influenced by the investigator's criteria for task scoring (see also Samuelsson, Hjelmquist, Naver, \& Bromstrand, 1995). The interval between neurological insult and time of testing may also substantially alter the apparent sensitivity of a test. As the prevalence of neglect decreases as time postinsult increases, the same test would be expected to identify fewer subjects with neglect later in the course of the illness.

Nevertheless, there are some generalizations to be drawn from studies of neglect incidence and prevalence. The sensitivity of a test may be greatly influenced by specific and, in some instances, seemingly minor differences in stimulus attributes. For example, bisection of long (e.g., $20 \mathrm{~cm}$ ) lines is more likely to detect a spatial bias than the use of short lines (Azouvi, Samuel, et al., 2002); tested with very short lines, patients may actually demonstrate contralesional "wrong-way" bias (the "crossover effect," Chatterjee, 1995). Most studies have found that test sensitivity of cancellation tasks is improved by increasing the visual similarity between the targets and the foils (Azouvi, Samuel, et al., 2002; Halligan, Marshall, et al., 1989) and increasing the number of distracting stimuli (Chatterjee, Mennemeier, \& Heilman, 1992). Placing the stimuli in contralesional space (Heilman \& Valenstein, 1979) can increase the sensitivity of both the line bisection and cancellation tasks (Lee et al., 2004; Rapcsak, Verfaellie, Fleet, \& Heilman, 1989).

Another consistent finding is that multiple tests are more sensitive than a single test (Azouvi, Samuel, et al., 2002; Halligan, Cockburn, \& Wilson, 1991). Therefore, most clinicians and researchers use a combination of tests, such as the six tests incorporated in the Behavioral Inattention Test: line crossing, letter cancellation, star cancellation, figure copying, line bisection, and representational drawing (Wilson et al., 1987).

Finally, of particular significance is the fact that making a task more resource demanding in any way, even by requiring a patient to engage in a verbal or calculation task to identify whether or not a stimulus is a target, will increase the sensitivity of neglect (i.e., will increase the spatial bias in responding, Mennemeier, Morris, \& Heilman, 2004). Although spatial neglect is most common in contralesional viewer centered (i.e., egocentric) hemispace, it may also be exhibited in environmental (Ladavas, 1987) and object centered coordinate systems (Hillis \& Caramazza, 1995). Neglect can also be ipsilesional (Kwon \& Heilman, 1991).

Test-retest reliability of these measures has rarely been documented. However, any test to be used as an outcome measure for treatment trials will need to be shown to have a high test-retest reliability, as well as high interjudge reliability in scoring.

\section{New Directions}

The tasks currently employed to assess neglect suffer from a number of limitations. First, the most commonly used tasks (e.g., cancellation tasks) provide a sensitive measure of spatial biases in attention in peripersonal space but are insensitive to subtypes of neglect. Thus, these tests do not assess some forms of neglect (e.g., personal neglect) and fail to distinguish between puta- 
tive sensory/attentional and motor/intentional subtypes of neglect. In light of the potential implications of these subtypes for response to treatment, this represents a significant limitation.

A second limitation of currently available tests is that they may be insensitive to subtle or mild forms of neglect. Neglect symptoms may be more severe in busy, attentionally demanding real-world environments than when the patient is sitting at a desk in a quiet office. In a recent large-scale study, right-hemisphere stroke patients were classified as exhibiting neglect or not on the basis of standard paper-and-pencil tests (Buxbaum, Ferraro, Veramonti, et al., 2004). Physical and occupational therapists were independently asked whether they thought neglect was present; for 15 subjects, therapists disagreed with the classification (neglect, no neglect) based on experimental tests. In $87 \%(13 / 15)$ of these patients, clinicians observed neglect, whereas the standard paper-and-pencil measures did not. These data suggest that the paper-and-pencil tests used in the study systematically underestimated the presence of neglect. One likely explanation for this discrepancy is that clinicians engaged the patients in more complex, resource-demanding activities. In light of these considerations, there is a need to develop additional measures of neglect that are sensitive to the following issues.

First, tasks should be sensitive to potential subtypes of neglect. Second, tests should cover a wide range of impairment severity, including measures that are low in resource demands, so that patients with severe neglect will be testable, as well as measures that are sufficiently difficult to detect very subtle neglect. Third, tasks assessing neglect in real-world settings are needed. These tasks may incorporate conflicting instructions or irrelevant stimuli, making them more sensitive to assess abnormal spatial biases that occur only when the patient is distracted (e.g., Barrett, Schwartz, Crucian, Kim, \& Heilman, 2000) or attentional resources are taxed. Fourth, tasks assessing disorders that are frequently associated with neglect are important because these disorders may strongly influence response to treatment. Currently, assessment of these related disorders often depends on behavioral observations and rating scales. Several measures of anosognosia have been developed (e.g., Azouvi, Olivier, et al., 2003; Bisiach, Vallar, Perani, Papagno, \& Berti, 1986); these measures appear to be infrequently employed. Bedside or easily administered tasks assessing sustained attention and/or effort would be most useful. Fifth, tasks assessing navigation are needed. Although most clinicians would likely agree that the ability to safely navigate in a complex environment is crucial to everyday life, a recent literature search revealed only one report of an obstacle-course measure of wheelchair mobility (Webster, Roades, et al., 1995; Webster, Cottam, et al., 1989). More importantly, the obstacle-course measure accurately predicted frequency of falls.
Virtual reality (VR) technology offers a potentially useful means by which navigation and other activities performed in extrapersonal space may be safely assessed. VR can be used to develop obstacle detection and avoidance tasks. VR tests appear to offer many advantages relative to traditional tasks. VR places no constraints on the size of the virtual environment, and enables manipulation of the environment with ease not possible in the clinical setting. It also provides data on many performance measures such as times to complete various goals and subgoals, number of obstacles hit on each side, and the number of turns to the right or left. VR may also provide a transparent means of pointing out patients' strengths and weaknesses to themselves and to caregivers. Several studies suggest that the VR environment may be more sensitive to detecting deficits in neglect than typical clinical tests (McGeorge et al., 2001; Mendozzi, Motta, Barbieri, Alpini, \& Pugnetti, 1998).

Finally, we note that some progress has been made toward developing desirable assessment tools. The Behavioral Inattention Test (Wilson et al., 1987) has been used widely and represents an important first step. The Naturalistic Action Test (NAT, www.tvtc.com/ publications/TestProd.asp?TestID=3) also appears promising. The NAT ranges in degree of difficulty so it is feasible with many (but probably not very severe) patients, and provides information of direct clinical relevance (tasks are activities of daily living such as packing a lunch box). It contains a lateralized attention scale that may be sensitive to a lateralized attentional impairment and is correlated with an ipsilesional minus contralesional score from a computerized task requiring responses to lateralized targets (Schwartz et al., 1999). Lastly, the Catherine Bergego Scale (Bergego et al., 1995), which rates neglect on a 4-point scale in 10 behavioral tasks (e.g., grooming, eating off a plate, maneuvering around furniture), may be more sensitive to pathological spatial bias than traditional paper-andpencil tasks and has been found to be reliable and valid (Azouvi, Olivier, et al., 2003), although it only assessed left-sided neglect.

\section{TREATMENT OF NEGLECT: CURRENT APPROACHES}

Two "evidence-based" analyses summarizing treatments for neglect have recently been published (Bowen, Lincoln, \& Dewey, 2002; Cicerone et al., 2000). Although the reports disagreed on the quality of evidence provided by some of the studies reviewed, they both supported the use of a "top-down," verbally mediated, "scanning therapy" approach. Any rehabilitative treatment may be defined as top-down-providing clients with response systems, or strategies, via external agency_or "bottom-up"-attempting to manipulate 
external stimuli or enhance innate attention- or actiondirecting systems. In top-down treatments, the patient assumes full responsibility for initiating use of therapeutic tools under future specific or general circumstances. An example of this treatment approach is scanning training, by urging patients to look and orient leftward with or without the use of tactile and visual aids.

Bottom-up strategies attempt to rearrange or enhance external stimuli to take advantage of inherent salience properties of perceptual information. An example is rearranging patient bed orientation so that examiners approach and stimuli appear, more often in the neglected hemispace. Bottom-up strategies may (e.g., limb activation, Robertson, McMillan, MacLeod, Edgeworth, \& Brock, 2002) or may not (e.g., medications) require patient agency.

Using top-down therapies in spatial neglect is tempting because patients and families may express the desire to understand the odd and sometimes bizarre deficits associated with the syndrome; however, top-down treatments are fundamentally atheoretical. Overwhelming evidence suggests that the primary spatial deficit in neglect is a bottom-up, stimulus-driven deficit inaccessible to conscious, insight-oriented self-modification, both directly in experimental analyses (e.g., Esterman et al., 2002) and in the lack of awareness that usually accompanies neglect (see discussion on anosognosia below). Thus, familiar approaches that emphasize client understanding or self-administration, unless coupled with a bottom-up management or treatment strategy, are likely to be ineffective.

Treatments can also be defined as endogenous (requiring nothing external except a therapist) or exogenous (requiring something external to the patient, such as a device) (e.g., prism lenses) or a specific environment. In many if not most settings, special devices for the treatment of neglect are not available for therapists to use. Thus, any exogenous therapy may have more limited impact on patient outcomes. However, casual clinical observation suggests that endogenous neglect treatments, such as medications, are rarely used.

Despite the concerted efforts of investigators during the past several decades, it appears to be widely assumed among cognitive scientists that treatment of neglect is ineffective. It is possible, however, that this is not true. The impression that treatments for neglect are ineffective may result from the multifactorial nature of the neglect syndrome. Thus, treatments may be effective for some symptoms but not others. Differential responses to treatments (i.e., some patients respond but others do not) may also masquerade as treatment failure. Because neglect rehabilitation lacks an observational literature describing past use of treatments and results of those recommendations, it is not possible at present to distinguish between these possibilities.

A summary of selected approaches targeting specific subtypes or symptoms of neglect is presented in Table 1.
Table 1. Treatments for Spatial Neglect, Divided by Potential Mechanism of Action

\begin{tabular}{ll}
\hline Perceptual Attentional & $\begin{array}{c}\text { Environmental-Motor } \\
\text { Remapping (Representational) }\end{array}$ \\
\hline Alerting & $\begin{array}{l}\text { Prism adaptation } \\
\text { Caloric stimulation } \\
\text { Galvanic stimulation/Neck } \\
\text { vibration }\end{array}$ \\
$\begin{array}{l}\text { Devices, medications } \\
\text { increasing arousal }\end{array}$ & Optikinetic stimulation \\
"Phasic alerting" self-cuing & Mirror therapy \\
Transdermal electrical nerve & (Virtual reality?) \\
Induced asymmetry & Motor Intentional \\
signal/noise ratio? & \\
\hline $\begin{array}{l}\text { Scanning training } \\
\text { Environmental manipulation }\end{array}$ & Constraint Induced Movement \\
Monocular patching & Therapy
\end{tabular}

Some of these treatments are discussed below. Details on all the numerous, useful reports on treatments for spatial neglect is unfortunately beyond the scope of this article, but the reader is referred to reviews by Chatterjee and Mennemeier (1998), Pierce and Buxbaum (2002), and Parton, Malhotra, and Husain (2004) for further information and specific references.

\section{Scanning Therapy}

This strategic instructional therapy, requiring no special equipment, urges patients to look and orient leftward, with or without the use of tactile, visual, or other aids. It has been used in combination with motor or habit training (e.g., Wiart et al., 1997). Scanning therapy is without question the most prevalent treatment for neglect, and the only treatment used or available in many settings.

A barrier to the effective use of scanning therapy is that it can take several different forms and is composed of several simultaneous interventions. At one extreme, scanning therapy can consist of almost insight-oriented verbal instruction; at the other, instructions are almost incidental to training eye movements or other orienting movements. As part of this therapy, therapists sit on 
the patient's neglected, hemiparetic side, resulting in asymmetric sensory stimulation. It is not known which aspects of the therapy are responsible for reported effectiveness in studies or meta-analyses.

\section{Pharmacological Therapy}

Although pharmacological interventions might be beneficial for spatial neglect, there is clinical consensus that some medications could potentially impair poststroke motor recovery. Potentially harmful agents include dopamine blockers, sedatives, anxiolytics, GABAergic agents, benzodiazepines, and anticholinergics (Goldstein, 1998). Most pharmacological interventions for neglect have centered on the use of dopaminergic and noradrenergic agents. Dopaminergic treatments such as bromocriptine (Barrett, Crucian, Schwartz, et al., 1999; Grujic et al., 1998; Hurford, Stringer, \& Jann, 1998; Fleet, Valenstein, Watson, \& Heilman, 1987), apomorphine (Geminiani, Bottini, \& Sterzi, 1998), carbidopa/levodopa (Mukand et al., 2001), and amantadine (Buxbaum, Ferraro, Whyte, Gershkoff, \& Coslett, in press) are based on the observation that unilateral dopaminergic ablation in animals produces a syndrome comparable to human neglect (Schwarting \& Huston, 1996). Noradrenergic treatments are based on observed abnormal arousal in neglect and reported benefit of stimulants in motor and language rehabilitation (e.g., Walker-Batson, Curtis, et al., 2001; e.g., Walker-Batson, Smith, Curtis, Unwin, \& Greenlee, 1995).

Barriers to pharmacological treatment of neglect include a paucity of reports compared to the likely numbers of actual treated patients; lack of information in available reports regarding clinical or radiologic patient characteristics that may alter treatment effect; and lack of information regarding appropriate medication dosing, poststroke treatment timing, or interaction with other treatments.

\section{Interventions to Improve Alerting}

Some therapies have been described as directed at promoting "sustained attention." Robertson, Tegner, Tham, Lo, and Nimmo-Smith (1995) describe a treatment using operant fading techniques to teach patients to self-cue with an auditory tone. In this study, eight patients with chronic neglect were taught to alert themselves; they found that subjects were improved with respect to sustained attention as well as neglect and that this improvement was sustained for the period of follow-up ( 5 to 12 days). It appears that the tone served as a "phasic alerting" cue that increased the likelihood of detecting stimuli on the neglected side of a stimulus array. The question remains how this technique might be used in a naturalistic context where the nature of the critical stimulus is less predictable than in the controlled experimental tasks used in these studies. Critically, whether subjects will habituate to such arousing stimuli if used regularly to support normal activities remains unknown. Such treatment, classified as bottom-up and exogenous (requires tone device), nevertheless requires patient agency for self-cuing.

\section{Selective Sensory Stimulation or Deprivation}

A variety of techniques have been used to enhance the salience of perceptual information from the neglected side. Investigators employed monocular eye patches, hemifield patches (e.g., the right visual field on both lenses of glasses), and prisms (without motor adaptation therapy; see below). Although benefit has been reported in some studies (e.g., Serfaty, Soroker, Glicksohn, Sepkuti, \& Myslobodsky, 1995), worsening of neglect with monocular patching may have occurred in some patients (e.g., Barrett, Crucian, \& Heilman, 2004; Barrett, Crucian, Beversdoft, et al., 2001). The explanation for this transient performance change is unclear; additionally, whether hemipatching or the use of other interventions in this category may induce performance worsening in some patients is not understood.

\section{Environmental-Motor Remapping}

These treatments, including the use of prisms accompanied by motor training (Rossetti et al., 1998), the use of caloric and galvanic vestibular stimulation (Vallar, Bottini, Rusconi, \& Sterzi, 1993), neck vibration (Karnath, 1995), and other treatments resulting in a somatic-visual mismatch (e.g., mirrors), may induce patients to move leftward via altered, illusory feedback. Although a consensus regarding the mechanism by which these treatments improve performance has not been achieved, one potential explanation for these interventions is that they induce a dynamic remapping between environmental location and location defined by the motor system and that attention is reallocated with reference to motor coordinates.

\section{Interventions to Improve Motor-Intention}

Treatments for directional or limb akinesia such as limbactivation therapy (Robertson, McMillan, et al., 2002; Robertson \& North, 1993) and the massed practice to the paretic limb of constraint-induced movement therapy (CIMT) (Mark \& Taub, 2004; Freeman, 2001), and tool use movement training (Ackroyd, Riddoch, Humphreys, Nightingale, \& Townsend, 2002) are all endogenous, partly top-down treatments used to increase a propensity to move leftward or with the left limbs.

Treatments have also targeted postural or ocular directional akinesia. Teaching patients to turn the trunk, the trunk and eyes, or the eyes leftward (Schindler \& Kerkhoff, 
1997; Young, Collins, \& Hren, 1983; Wiart et al., 1997; Diller \& Weinberg, 1977; Fanthome, Lincoln, Drummond, \& Walker, 1995; Weinberg et al., 1977) has been reported to improve neglect. These bottom-up methods, requiring patient agency, appear to be endogenous, except for Fathome et al. (1995), who had patients wear an adaptive device triggering a sound when they looked left. Bowen, Lincoln, and Dewey (2002) and Cicerone et al. (2000) disagreed in their evidence-based methodology reviews on cognitive rehabilitation about the quality of evidence provided by some of these studies, but both reviews conceded that published studies suggest these methods may result in functionally significant improvement. As noted above, scanning training can include treatment for postural or ocular directional akinesia, with patients taught to turn the trunk, the trunk and eyes, or the eyes leftward (e.g., Wiart et al., 1997).

\section{TREATMENT OF NEGLECT: NEW DIRECTIONS}

\section{Systems-Level Recommendations}

Given the current state of knowledge, it should be emphasized that considerations such as number of subjects and subject randomization are less important than sound scientific thinking. In order to study and treat neglect, a clear consensus definition of neglect, including functional disability, is needed. Potential confounding effects of interventions for unrelated problems (e.g., antidopaminergic GI medicines) on neglect rehabilitation need to be better defined and considered in the design of interventions.

Single-subject trials and case series reports are extremely useful to test hypotheses and generate novel ideas. These study methods are also valuable to falsify an existing hypothesis, report a novel treatment with a large effect size, and present a therapeutic method in detail so as to be fully replicable. The case series method allows one to generate hypotheses about demographic, lesion- or behavior-based subgroups, and to suggest potential confounds in the treatment or behavior being studied. Additionally, observational and natural history studies can clarify whether interactions involving multiple factors or outcomes may be relevant, whether high-investment treatments (e.g., computeradministered virtual reality) are feasible for widespread use and may be the only way of collecting data in settings where rigorous control is not possible or appropriate (e.g., the home). Single-subject and case series reports should include both neuropsychological and functional outcomes if possible.

Randomized controlled trials in groups or populations are important tools. These studies can demonstrate small (and large) effects that are crucial for treatment guidelines (e.g., possible detrimental effects). Particularly when control/comparison conditions are rigorously defined, potential subversion of randomiza- tion is acknowledged and controls put in place, and both neuropsychological and multiple functional outcome measures are examined over time, randomized control trials provide powerful leverage for regulation of health care and policy reform. Randomized control trials cannot be justified, however, without preliminary evidence regarding the type of treatment that is likely to be effective for particular types of neglect and information regarding the likely effect size. Given the current state of knowledge regarding neglect, randomized clinical trials, despite their obvious utility, do not appear to be appropriate.

\section{Systems-level Obstacles: Communicating with Clinical Science}

Partnering with the clinical community is crucial if effective observational research is to occur; this partnership must be based upon a perception of mutual benefit. If neglect rehabilitation is scientifically perceived as completely ineffective, theory and practice cannot be coordinated. If practitioners are convinced that one rehabilitation method is the only acceptable choice, they cannot ethically participate in any research practice that denies their patients this method. By not acknowledging the needs of such nonparticipating practitioners, academic rehabilitation denies itself a wealth of valuable experience with treatment outcomes, particularly negative data. Integrating education into research, and research into education, may aid in closing the gap between theory and practice. This might include sponsored mechanisms for career development of clinical researcher in cognitive rehabilitation. However, observational studies aimed at defining therapeutic interventions in specified groups across a variety of settings will also yield important data about variations in practice that will dictate in what directions the system should develop to increase effectiveness.

\section{Obstacles Originating in Rehabilitation Theory: Establishing Clinical Consensus}

Multicenter, collaborative work is needed to increase clinical consensus in defining and characterizing neglect. The Stroke Rehabilitation Team recognized a crucial need to allocate specific resources for collaborative work across institutions in order to increase these activities.

With respect to subject heterogeneity, it is very important that further feasibility studies are performed with observational methodology, examining neglect symptom subtyping in large groups of patients and its relation to functional outcome or treatment-oriented variables. Thus, regardless of reliability and stability from one measure to another or over time, efforts to obtain information regarding neglect subtypes should be in- 
corporated into future research designs. Additional data are also needed in comparing demographic, age, and geographic patient groups as well.

\section{KEY ISSUES AND QUESTIONS RELATING TO THE DEVELOPMENT OF TREATMENT FOR NEGLECT IN STROKE PATIENTS}

Investigations motivated by current accounts of attention, intention, and information processing have contributed greatly to the understanding of neglect and its related disorders. Theoretically motivated treatments have yielded promising results in several domains. Despite these advances, much remains to be done to translate these research insights into clinically relevant paradigms. We have attempted to identify several of the factors that currently limit the clinical application of these exciting observations and to suggest promising avenues and strategies for additional investigation. By marrying the theoretical sophistication of cognitive neuroscience with the opportunities and constraints that characterize the clinic, we hope that the often catastrophic consequences of neglect and related disorders may be ameliorated. The following issues may have important consequences for the rehabilitation of neglect but there are few or no data at present.

1. Pharmacologic interventions for alerting and sensory stimulation: Although treatments targeting the dopaminergic and noradrenergic neurotransmitter systems have shown some promise, there is reason to believe that medications targeting other systems may also be beneficial. Several lines of evidence suggest that norepinephrine, principally from the locus coeruleus, is important to the regulation of vigilance and arousal (Foote \& Morrison, 1987) and that there is right-hemisphere predominance in the distribution of norepinephrine (Oke, Keller, \& Adams, 1978). In light of these data, one might argue for a trial with agents such as atomoxetine (Strattera ${ }^{\mathrm{TM}}$ ) in the treatment of patients with neglect. Additionally, given that impaired arousal may contribute substantially to the disability associated with neglect, treatment with alerting medications such as modafinil (Provigil ${ }^{\mathrm{TM}}$ ) may be of benefit. Cholinergic agents may improve stimulus detection by altering a stimulus/noise ratio, but whether this would improve or worsen an asymmetric deficit is unclear.

2. Potential utility of combining pharmacologic and behavioral interventions: The benefits of pharmacologic interventions might be enhanced when combined with behavioral treatments. Sutton, Hovda, and Feeney (1989), for example, demonstrated that amphetamines improved beam walking in the rat when given in conjunction with exercise but not when given in the absence of exercise. Beneficial effects of amphetamines when paired with physical therapy have also been re- ported in neglect patients (Walker-Batson, Smith, et al., 1995; Crisostomo, Duncan, Propst, Dawson, \& Davis, 1988). Additionally, Walker-Batson et al. (2001) argued that amphetamine, when combined with speech therapy, improves aphasia. Scheidtmann, Fries, Muller, and Koenig (2001) also reported data from a double-blind study in which carbidopa/levodopa $(25 / 100 \mathrm{mg})$ was given $30 \mathrm{~min}$ prior to physical therapy for 3 weeks. Carbidopa/levodopa treatment was associated with greater motor recovery than placebo. Finally, Knecht et al. (2004) reported data from a double-blind study in normal subjects demonstrating that carbidopa/levodopa administered $90 \mathrm{~min}$ before training improved novel word learning. These reports provide strong support for the potential utility of combining behavioral and pharmacologic interventions.

3. Treatment of related/confounding behavioral disorders: We have previously reviewed data demonstrating that the incidence and severity of neglect may be substantially influenced by associated disorders such as impaired arousal. Given the evidence that neglect is associated with deficits in sustained attention and arousal and that interventions targeting arousal improve performance on several measures of neglect (see Robertson, 2001, for a review), investigation of treatments focusing on impaired arousal appear to be warranted.

As noted previously, anosognosia is frequently associated with neglect and may have an adverse effect on treatment outcome. This is an important issue for several reasons. First, indifference to illness may have an adverse impact on patient's engagement in rehabilitation. Second, anosodiaphoria, itself a consequence of the lesion, may limit the delivery of rehabilitation services. The relationship between anosognosia and outcome from rehabilitation warrants systematic investigation. For example, does anosognosia/anosodiaphoria prevent patients from seeking therapy? Additionally, the relationship between anosognosia/anosodiaphoria and response to treatment should be investigated. If anosognosia/ anosodiaphoria is associated with poor outcome, it would be important to determine if the anosognosia/ anosodiaphoria is specific for neglect, the manifestations of neglect, or is more general. If it is specific, we might be able to find other means of motivating patients with neglect and anosognosia/anosodiaphoria to actively participate in interventional programs by, for example, using game-based strategies (Wood et al., 2003). If anosognosia/anosodiaphoria in the context of neglect is associated with depression, aggressive treatment of depression would be warranted. Finally, if anosognosia/anosodiaphoria in this context extends to a phenomenon not related to neglect but is not related to depression it would be important to explore behavioral or pharmacological treatments for anosognosia/ anosodiaphoria. 
4. Potential negative effect of selective stimulus deprivation: As above, because monocular patching may adversely affect neglect or induce neglect in vulnerable patients, it is possible that other interventions resulting in selective stimulus deprivation may worsen neglect (e.g., CIMT, prisms, and interventions used for other purposes such as elastic gloves or stockings to decrease limb edema, or orthotic devices). This warrants investigation.

5. Environmental-motor remapping via virtual reality (VR): Although there is an encouraging number of new studies focusing on the use of VR as a rehabilitation assessment and treatment tool in patients with stroke and traumatic brain injury, there have been very few published studies on the VR treatment of neglect. One exception is the Castiello et al. (2004) study, which provided a striking demonstration of possible benefit of VR in neglect rehabilitation. Patients were trained to reach for unseen objects whose virtual image was projected on a screen while wearing a dataglove that captured their hand movements and projected these, too, as images on the screen. The virtual environment permitted manipulation of the relationship between the actual hand and object positions and their perceived positions. Practice using the apparatus when there was a mismatch in this relationship resulted in significant improvements in neglect that persisted for several hours.

Other relevant studies in this area are several that have supported the utility of VR training for route finding in developmentally disabled populations (Cromby, Standen, Newman, \& Taasker, 1996), disabled children (Stanton, Foreman, \& Wilson, 1998), and adults with amnesia (Brooks et al., 1999). VR applications have also been used with success in the rehabilitation of poststroke motor disorders (Deutsch, Latonio, Burdea, \& Boian, 2001; Jack et al., 2001). An important concept regarding the feasibility of VR is that a full, computerenhanced system is not required to give a convincing somatic/motor illusion. Mirror therapy, in which patients observe movements in a mirror that appear to be the movements of their paretic arm, is a form of virtual-reality training, as is the video right-left reversal apparatus used by $\mathrm{Na}$ et al. (1998). The utility of assessing and rehabilitating neglect using VR is an area that appears ripe for study.

6. Physiological treatments to enbance brain recovery: Although the evidence is limited, several investigators have reported studies in which transcranial magnetic stimulation (TMS) was employed for remediation. Naeser et al. (2005) have reported modest success in treating severe chronic aphasics with TMS delivered to the contralesional (right) Broca's area. There is at least one report of modest improvement in neglect with TMS. This appears worth pursuing, preferably in investigations combining TMS with behavioral interventions.

\section{Acknowledgments}

This project was supported by the National Institute of Neurological Disorders and Stroke. Dr. H. Branch Coslett performed critical manuscript editing and organization for The Stroke Rehabilitation Team. This article has been developed from the research and discussions carried out by the NINDS Cognitive Rehabilitation Initiative Working Group (see September 23-24, 2004, workshop Executive Summary at www.ninds.nih.gov/ news_and_events/proceedings/execsumm07_19_05.htm).

We thank Drs. Emmeline Edwards, Robert Finkelstein, and Mary Ellen Michel for excellent comments on an earlier version of this manuscript; we also thank Dr. Biao Tian and Rebecca Desrocher for editorial assistance and help in reformatting this manuscript.

Reprint requests should be sent to Emmeline Edwards, National Institute of Neurological Disorders and Stroke, 6001 Executive Boulevard, Room 3305, Bethesda, MD 20892-9531, or via e-mail: ee48r@nih.gov.

\section{REFERENCES}

Ackroyd, K., Riddoch, M. J., Humphreys, G. W., Nightingale, S., \& Townsend, S. (2002). Widening the sphere of influence: Using a tool to extend extrapersonal visual space in a patient with severe neglect. Neurocase, 8, 1-12.

Adair, J. C., Na, D. L., Schwartz, R. L., Fennell, E. M., Gilmore, R. L., \& Heilman, K. M. (1995). Anosognosia for hemiplegia: Test of the personal neglect hypothesis. Neurology, 45 , 2195-2199.

Adair, J. C., Na, D. L., Schwartz, R. L., \& Heilman, K. M. (1998). Analysis of primary and secondary influences on spatial neglect. Brain and Cognition, 37, 351-367.

Adair, J. C., Na, D. L., Schwartz, R. L., \& Heilman, K. M. (2003). Caloric stimulation in neglect: Evaluation of response as a function of neglect type. Iournal of the International Neuropsychological Societv, 9, 983-988.

Albert, M. L. (1973). A simple test of visual neglect. Neurology, 23, 658-664.

Azouvi, P., Olivier, S., de Montety, G., Samuel, C., LouisDreyfus, A., \& Tesio, L. (2003). Behavioral assessment of unilateral neglect: Study of the psychometric properties of the Catherine Bergego Scale. Archives of Phvsical Medicine and Rehabilitation, 84, 51-57.

Azouvi, P., Samuel, C., Louis-Dreyfus, A., Bernati, T., Bartolomeo, P., Beis, J. M., Chokron, S., Leclercq, M., Marchal, F., Martin, Y., De Montety, G., Olivier, S., Perennou, D., Pradat-Diehl, P., Prairial, C., Rode, G., Sieroff, E., Wiart, L., \& Rousseaux, M. (2002). Sensitivity of clinical and behavioral tests of spatial neglect after right hemisphere stroke. Journal of Neurology. Neurosurgery and Psychiatry, 73, 160-166.

Babinski, J. (1914). Contribution à l'étude des troubles mentaux dans l'hemisplegic organique cérébrale (anosognosie). Revista de Neurologia, 27, 845-848.

Bachman, L., Fein, G., Davenport, L., \& Price, L. (1993). The Indented Paragraph Reading Test in the assessment of left hemi-neglect. Archives of Clinical Neuropsvchologv 8, 485-496.

Barrett, A. M., Crucian, G. P., Beversdorf, D. Q., \& Heilman, K. M. (2001). Monocular patching may worsen sensoryattentional neglect: A case report. Archives of Phvsical Medicine and Rehabilitation, 82, 516-518.

Barrett, A. M., Crucian, G. P., \& Heilman, K. M. (2004). Adverse effect of eye patching on spatial attention in a patient with thalamic hemorrhage. Archives of Physical Medicine and Rebabilitation, 85, 1017-1020. 
Barrett, A. M., Crucian, G. P., Schwartz, R. L., \& Heilman, K. M. (1999). Adverse effect of dopamine agonist therapy in a patient with motor-intentional neglect. Archives of Phvsical Medicine and Rehabilitation, 80, 600-603.

Barrett, A. M., Schwartz, R. L., Crucian, G. P., Kim, M., \& Heilman, K. M. (2000). Attentional grasp in far extrapersonal space after thalamic infarction.

Neuropsychologia. 38, 778-784.

Barrett, A. M., Peterlin, B. L., \& Heilman, K. M. (2003). Ipsilateral neglect versus hemianopic compensation. Neurology, 61, 120-123.

Bergego, C., Azouvi, P., Samuel, C., Marchal, F., Louis-Dreyfus, A., Jokic, C., Morin, L., Renard, C., Pradat-Diehl, P., \& Deloche, G. (1995). Validation d'une échelle d'évaluation fonctionnelle de l'héminégligence dans la vie quotidienne: L'échelle CB. Annales de Réadaptation et de Médecine Physiques, 38, 183-189.

Beschin, N., \& Robertson, I. H. (1997). Personal versus extrapersonal neglect: A group study of their dissociation using a reliable clinical test. Cortex, 33, 379-384.

Bisiach, E., Geminiani, G., Berti, A., \& Rusconi, M. L. (1990). Perceptual and premotor factors of unilateral neglect. Neurology, 40, 1278-1281.

Bisiach, E., Perani, D., Vallar, G., \& Berti, A. (1986).

Unilateral neglect: Personal and extra-personal. Neuropsvchologia, 24, 759-767.

Bisiach, E., Vallar, G., Perani, D., Papagno, C., \& Berti, A. (1986). Unawareness of disease following lesions of the right hemisphere: Anosognosia for hemiplegia and anosognosia for hemianopia. Neuropsvchologia, 24, 471-482.

Bowen, A., Lincoln, N. B., \& Dewey, M. E. (2002). Spatial neglect: Is rehabilitation effective? Stroke, 33, 2728-2729.

Bowen, A., McKenna, K., \& Tallis, R. C. (1999). Reasons for variability in the reported rate of occurrence of unilateral spatial neglect after stroke. Stroke, 30, 1196-1202.

Brooks, B., McNeil, J., Rose, F., Greenwood, R. J., Attree, E., \& Leadbetter, A. (1999). Route learning in a case of amnesia: A preliminary investigation into the efficacy of training in a virtual environment. Neuropsychological Rehabilitation 9, 63-76.

Buxbaum, L. J., Ferraro, M., Whyte, J., Gershkoff, A., \& Coslett, H. B. (in press). Amantadine treatment of hemispatial neglect: A double blind, placebo-controlled study. American Journal of Physical Medicine and Rehabilitation.

Buxbaum, L. J., Ferraro, M. K., Veramonti, T., Farne, A., Whyte, J., Ladavas, E., Frassinetti, F., \& Coslett, H. B. (2004). Hemispatial neglect: Subtypes, neuroanatomy, and disability. Neurology, 62, 749-756.

Caplan, B. (1987). Assessment of unilateral neglect: A new reading test. Journal of Clinical and Experimental Neuropsychology 9, 359-364.

Cassidy, T. P., Bruce, D. W., Lewis, S., \& Gray, C. S. (1999). The association of visual field deficits and visuo-spatial neglect in acute right-hemisphere stroke patients. Age and Ageing, 28, 257-260.

Castiello, U., Lusher, D., Burton, C., Glover, S., \& Disler, P. (2004). Improving left hemispatial neglect using virtual reality. Neurology, 62, 1958-1962.

Chatterjee, A. (1995). Cross-over, completion and confabulation in unilateral spatial neglect. Brain, 118, 455-465.

Chatterjee, A., \& Mennemier, M. (1998). Diagnosis and treatment of spatial neglect. In R. B. Lazar (Ed.), Principles of neurologic rebabilitation (pp. 597-612). New York: McGraw-Hill

Chatterjee, A., Mennemeier, M., \& Heilman, K. M. (1992). A stimulus-response relationship in unilateral neglect: The power function. Neuropsvchologia. 30, 1101-1108.
Cherney, L. R., Halper, A. S., Kwasnica, C. M., Harvey, R. L., \& Zhang, M. (2001). Recovery of functional status after right hemisphere stroke: Relationship with unilateral neglect. Archives of Phusical Medicine and Rehabilitation, 82, 322-328.

Cicerone, K. D., Dahlberg, C., Kalmar, K., Langenbahn, D. M., Malec, J. F., Bergquist, T. F., Felicetti, T., Giacino, J. T., Harley, J. P., Harrington, D. E., Herzog, J., Kneipp, S., Laatsch, L., \& Morse, P. A. (2000). Evidence-based cognitive rehabilitation: Recommendations for clinical practice. Archives of Physical Medicine and Rebabilitation, 81, 1596-1615.

Coslett, H. B., Bowers, D., Fitzpatrick, E., Haws, B., \& Heilman, K. M. (1990). Directional hypokinesia and hemispatial inattention in neglect. Brain, 113, 475-486.

Coslett, H. B., \& Heilman, K. M. (1989). Hemihypokinesia after right hemisphere stroke. Brain and Cognition, 9, 267-278.

Crisostomo, E. A., Duncan, P. W., Propst, M., Dawson, D. V., \& Davis, J. N. (1988). Evidence that amphetamine with physical therapy promotes recovery of motor function in stroke patients. Annals of Neurologv, 23, 94-97.

Critchley, M. (1957). Observations on anosodiaphoria. L'Encephale, 46, 540-546.

Cromby, J., Standen, P., Newman, J., \& Taasker, H. (1996). Successful transfer to the real world of skills practiced in a virtual environment by a student with severe learning disabilities. Paper presented at the 1st European Conference on Diability, Virtual Reality, and Associated Technologies, Reading, UK.

Deutsch, J. E., Latonio, J., Burdea, G., \& Boian, R. (2001). Post-stroke rehabilitation with the Rutgers Ankle System: A case study. Presence-Teleoperators and Virtual Environments, 10, 416-430.

Diller, L., \& Weinberg, J. (1977). Hemi-inattention in rehabilitation: The evolution of a rational remediation program. Advances in Neurology, 18, 63-82.

Duncan, J., Bundesen, C., Olson, A., Humphreys, G., Chavda, S., \& Shibuya, H. (1999). Systematic analysis of deficits in visual attention. Journal of Experimental Psvchology: General, 128, 450-478.

Esterman, M., McGlinchey-Berroth, R., Verfaellie, M., Grande, L., Kilduff, P., \& Milberg, W. (2002). Aware and unaware perception in hemispatial neglect: Evidence from a stem completion priming task. Cortex, 38, 233-246.

Fanthome, Y., Lincoln, N. B., Drummond, A., \& Walker, M. F. (1995). The treatment of visual neglect using feedback of eye movements: A pilot study. Disability and Rebabilitation, 17, 413-417.

Fleet, W. S., Valenstein, E., Watson, R. T., \& Heilman, K. M. (1987). Dopamine agonist therapy for neglect in humans. Neurology, 37, 1765-1770.

Foote, S. L., \& Morrison, J. H. (1987). Development of the noradrenergic, serotonergic, and dopaminergic innervation of neocortex. Current Topics in Developmental Biology, 21, 391-423.

Freeman, E. (2001). Unilateral spatial neglect: New treatment approaches with potential application to occupational therapy. American Journal of Occupational Therapy, 55, 401-408.

Gainotti, G. (1972). Emotional behavior and hemispheric side of the lesion. Cortex, 8, 41-55.

Gainotti, G., D'Erme, P., \& Bartolomeo, P. (1991). Early orientation of attention toward the half space ipsilateral to the lesion in patients with unilateral brain damage. Journal of Neurology. Neurosurgery. and Psychiatry. 54, 1082-1089. 
Gauthier, L., Dehaut, F., \& Joanette, Y. (1989). The Bell's test: A quantitative and qualitative test for visual neglect. International Journal of Clinical Neuropsychology, 11, 49-54.

Geminiani, G., Bottini, G., \& Sterzi, R. (1998). Dopaminergic stimulation in unilateral neglect. Journal of Neurologv. Neurosurgerv and Psychiatry, 65, 344-347.

Goldstein, L. B. (1998). Potential effects of common drugs on stroke recovery. Archives of Neurology, 55, 454-456.

Grujic, Z., Mapstone, M., Gitelman, D. R., Johnson, N., Weintraub, S., Hays, A., Kwasnica, C., Harvey, R., \& Mesulam, M. M. (1998). Dopamine agonists reorient visual exploration away from the neglected hemispace. Neurology, 51, 1395-1398.

Guariglia, C., \& Antonucci, G. (1992). Personal and extrapersonal space: A case of neglect dissociation. Neuropsvchologia, 30, 1001-1009.

Halligan, P. W., Cockburn, J., \& Wilson, B. (1991). The behavioral assessment of visual neglect. Neuropsychological Rebabilitation, 1, 5-32.

Halligan, P. W., Marshall, J. C., \& Wade, D. T. (1989). Visuospatial neglect: Underlying factors and test sensitivity. Lancet, 2, 908-911.

Harvey, M., Kramer-McCaffery, T., Dow, L., Murphy, P. J., \& Gilchrist, I. D. (2002). Categorization of 'perceptual' and 'premotor' neglect patients across different tasks: Is there strong evidence for a dichotomy? Neuropsvchologia, 40, 1387-1395.

Heilman, K. M., Schwartz, H. D., \& Watson, R. T. (1978). Hypoarousal in patients with the neglect syndrome and emotional indifference. Neurology, 28, 229-232.

Heilman, K. M., \& Valenstein, E. (1979). Mechanisms underlying hemispatial neglect. Annals of Neurology, 5, 166-170.

Heilman, K. M., \& Van Den Abell, T. (1980). Right hemisphere dominance for attention: The mechanism underlying hemispheric asymmetries of inattention (neglect). Neurology, 30, 327-330.

Heilman, K. M., Watson, R. T., \& Valenstein, E. (1985). Neglect and related disorders. In K. M. Heilman \& E. Valenstein (eds.). Clinical Neuropsychology (2nd ed.). New York: Oxford University Press.

Hillis, A. E., \& Caramazza, A. (1995). A framework for interpreting distinct patterns of hemispatial neglect. Neurocase, 1, 189-207.

Hurford, P., Stringer, A. Y., \& Jann, B. (1998). Neuropharmacologic treatment of hemineglect: A case report comparing bromocriptine and methylphenidate. Archives of Phvsical Medicine and Rebabilitation, 79, 346-349.

Ito, T., Hirayama, K., Yamawaki, R., Kondo, Y., Sakai, S., Kondo, T., \& Yamadori, A. (2003). [Unawareness for homonymous visual field defect]. No To Shinkei, 55, 869-877.

Jack, D., Boian, R., Merians, A. S., Tremaine, M., Burdea, G. C., Adamovich, S. V., Recce, M., \& Poizner, H. (2001). Virtual reality-enhanced stroke rehabilitation. IEEE Transactions on Neural Systems and Rebabilitation Engineering 9, 308-318.

Karnath, H. O. (1995). Transcutaneous electrical stimulation and vibration of neck muscles in neglect. Experimental Brain Research, 105, 321-325.

Katz, N., Hartman-Maeir, A., Ring, H., \& Soroker, N. (1999). Functional disability and rehabilitation outcome in right hemisphere damaged patients with and without unilateral spatial neglect. Archives of Physical Medicine and Rebabilitation, 80, 379-384.
Knecht, S., Breitenstein, C., Bushuven, S., Wailke, S., Kamping, S., Floel, A., Zwitserlood, P., \& Ringelstein, E. B. (2004). Levodopa: Faster and better word learning in normal humans. Annals of Neurology, 56, 20-26.

Kwon, S. E., \& Heilman, K. M. (1991). Ipsilateral neglect in a patient following a unilateral frontal lesion. Neurology, 41, 2001-2004.

Ladavas, E. (1987). Is the hemispatial deficit produced by right parietal lobe damage associated with retinal or gravitational coordinates? Brain, 110, 167-180.

Laurent-Vannier, A., Pradat-Diehl, P., Chevignard, M., Abada, G., \& De Agostini, M. (2003). Spatial and motor neglect in children. Neurology, 60, 202-207.

Lee, B. H., Kang, S. J., Park, J. M., Son, Y., Lee, K. H., Adair, J. C., Heilman, K. M., \& Na, D. L. (2004). The Character-line Bisection Task: A new test for hemispatial neglect. Neuropsychologia, 42, 1715-1724.

Mapstone, M., Weintraub, S., Nowinski, C., Kaptanoglu, G., Gitelman, D. R., \& Mesulam, M. M. (2003). Cerebral hemispheric specialization for spatial attention: Spatial distribution of search-related eye fixations in the absence of neglect. Neuropsvchologia, 41, 1396-1409.

Marcel, A. J., Tegner, R., \& Nimmo-Smith, I. (2004). Anosognosia for plegia: Specificity, extension, partiality and disunity of bodily unawareness. Cortex, 40, 19-40.

Mark, V. W., \& Taub, E. (2004). Constraint-induced movement therapy for chronic stroke hemiparesis and other disabilities. Restorative Neurology and Neuroscience, 22, 317-336.

McGeorge, P., Phillips, L., Crawford, J., Garden, S., Della Sala, S., Milne, A. B., Hamilton, S., \& Callender, J. S. (2001). Using virtual environments in the assessment of executive dysfunction. Presence-Teleoperators and Virtual Environments, 10, 375-383.

McGlinchey-Berroth, R., Bullis, D. P., Milberg, W. P., Verfaellie, M., Alexander, M., \& D'Esposito, M. (1996). Assessment of neglect reveals dissociable behavioral but not neuroanatomical subtypes. Journal of the International Neuropsychological Society, 2, 441-451.

Mendozzi, L., Motta, A., Barbieri, E., Alpini, D., \& Pugnetti, L. (1998). The application of virtual reality to document coping deficits after a stroke: Report of a case. Cuberpsychology and Behavior, 1, 79-91.

Mennemeier, M. S., Morris, M., \& Heilman, K. M. (2004). Just thinking about targets can aggravate neglect on cancellation tasks. Neurocase, 10, 29-38.

Milner, A. D., Brechmann, M., \& Pagliarini, L. (1992). To halve and to halve not: An analysis of line bisection judgments in normal subjects. Neuropsvchologia, 30, $515-526$.

Mukand, J. A., Guilmette, T. J., Allen, D. G., Brown, L. K., Brown, S. L., Tober, K. L., \& Vandyck, W. R. (2001). Dopaminergic therapy with carbidopa L-dopa for left neglect after stroke: A case series. Archives of Physical Medicine and Rehabilitation, 82, 1279-1282.

Muller-Oehring, E. M., Kasten, E., Poggel, D. A., Schulte, T., Strasburger, H., \& Sabel, B. A. (2003). Neglect and hemianopia superimposed. Journal of Clinical and Experimental Neuropsychology, 25, 1154-1168.

Na, D. L., Adair, J. C., Williamson, D. J., Schwartz, R. L., Haws, B., \& Heilman, K. M. (1998). Dissociation of sensory-attentional from motor-intentional neglect. Journal of Neurology. Neurosurgerv. and Psychiatry 64, 331-338.

Nadeau, S. E., \& Heilman, K. M. (1991). Gaze-dependent hemianopia without hemispatial neglect. Neurology, 41, $1244-1250$. 
Naeser, M. A., Martin, P. I., Nicholas, M., Baker, E. H., Seekins, H. E., Kobayashi, M., Theoret, H., Fregni, F., Tormos, J. M., Kurland, J., Doron, K. W., \& Pascual-Leone, A. (2005). TMS to right Broca's area: Improvement in picture naming in chronic aphasia. Neurocase, 11, 182-193.

Nico, D. (1996). Detecting directional hypokinesia: The epidiascope technique. Neuropsychologia, 34, 471-474.

Ogden, J. A. (1985). Anterior-posterior interhemispheric differences in the loci of lesions producing visual hemineglect. Brain and Cognition, 4, 59-75.

Oke, A., Keller, R., \& Adams, R. N. (1978). Dopamine and norepinephrine enhancement in discrete rat brain regions following neonatal 6-hydroxydopamine treatment. Brain Research, 148, 245-250.

Ota, H., Fujii, T., Suzuki, K., Fukatsu, R., \& Yamadori, A. (2001). Dissociation of body-centered and stimulus-centered representations in unilateral neglect. Neurology, 57, 2064-2069.

Paolucci, S., Antonucci, G., Grasso, M. G., \& Pizzamiglio, L. (2001). The role of unilateral spatial neglect in rehabilitation of right brain-damaged ischemic stroke patients: A matched comparison. Archives of Physical Medicine and Rehabilitation, 82, 743-749.

Parton, A., Malhotra, P., \& Husain, M. (2004). Hemispatial neglect. Journal of Neurology, Neurosurgery, and Psychiatry, 75, 13-21.

Pierce, S. R., \& Buxbaum, L. J. (2002). Treatments of unilateral neglect: A review. Archives of Physical Medicine and Rehabilitation, 83, 256-268.

Rapcsak, S. Z., Verfaellie, M., Fleet, W. S., \& Heilman, K. M. (1989). Selective attention in hemispatial neglect. Archives of Neurology, 46, 178-182.

Ringman, J. M., Saver, J. L., Woolson, R. F., Clarke, W. R., \& Adams, H. P. (2004). Frequency, risk factors, anatomy, and course of unilateral neglect in an acute stroke cohort. Neurology, 63, 468-474.

Robertson, I. H. (1998). Visual attention: Controlling what we see and do. Current biology, 8, R232-R234.

Robertson, I. H. (2001). Do we need the "lateral" in unilateral neglect? Spatially nonselective attention deficits in unilateral neglect and their implications for rehabilitation. Neuroimage, 14, S85-S90.

Robertson, I. H., Manly, T., Beschin, N., Daini, R., Haeske-Dewick, H., Homberg, V., Jehkonen, M., Pizzamiglio, G., Shiel, A., \& Weber, E. (1997). Auditory sustained attention is a marker of unilateral spatial neglect. Neuropsvchologia. 35, 1527-1532.

Robertson, I. H., McMillan, T. M., MacLeod, E., Edgeworth, J., \& Brock, D. (2002). Rehabilitation by limb activation training reduces left-side motor impairment in unilateral neglect patients: A single blind randomized control trial. Neuropsychological Rehabilitation, 12, 439-454.

Robertson, I. H., \& North, N. (1993). Active and passive activation of left limbs: Influence on visual and sensory neglect. Neuropsychologia. 31, 293-300.

Robertson, I. H., Tegner, R., Tham, K., Lo, A., \& Nimmo-Smith, I. (1995). Sustained attention training for unilateral neglect: Theoretical and rehabilitation implications. Lournal of Clinical and Experimental Neuropsychology 17, 416-430.

Rossetti, Y., Rode, G., Pisella, L., Farne, A., Li, L., Boisson, D., \& Perenin, M. T. (1998). Prism adaptation to a rightward optical deviation rehabilitates left hemispatial neglect. Nature, 395, 166-169.

Samuelsson, H., Hjelmquist, E., Naver, H., \& Bromstrand, C. (1995). Different criteria in the assessment of visuospatial neglect. Lournal of Neurology. Neurosurgery. and Psvchiatry, 58, 114-115.
Scheidtmann, K., Fries, W., Muller, F., \& Koenig, E. (2001). Effect of levodopa in combination with physiotherapy on functional motor recovery after stroke: A prospective, randomized, double-blind study. Lancet, 358, 787-790.

Schindler, I., \& Kerkhoff, G. (1997). Head and trunk orientation modulate visual neglect. NeuroReport. 8 , 2681-2685.

Schwarting, R. K., \& Huston, J. P. (1996). The unilateral 6-hydroxydopamine lesion model in behavioral brain research. Analysis of functional deficits, recovery and treatments. Progress in Neurobiology, 50, 275-331.

Schwartz, M. F., Buxbaum, L. J., Montgomery, M. W., Fitzpatrick-DeSalme, E., Hart, T., Ferraro, M., Lee, S. S., \& Coslett, H. B. (1999). Naturalistic action production following right hemisphere stroke. Neuropsychologia. 37, 51-66.

Serfaty, C., Soroker, N., Glicksohn, J., Sepkuti, J., \& Myslobodsky, M. S. (1995). Does monocular viewing improve target detection in hemispatial neglect? Restorative Neurology and Neurosciences, 9, 77-83.

Smania, N., \& Aglioti, S. (1995). Sensory and spatial components of somaesthetic deficits following right brain damage. Neurology, 45, 1725-1730.

Stanton, D., Foreman, N., \& Wilson, P. N. (1998). Uses of virtual reality in clinical training: Developing the spatial skills of children with mobility impairments. Studies in Health Technology and Informatics, 58, 219-232.

Sterzi, R., Bottini, G., Celani, M. G., Righetti, E., Lamassa, M., Ricci, S., \& Vallar, G. (1993). Hemianopia, hemianaesthesia, and hemiplegia after right and left hemisphere damage. A hemispheric difference. Iournal of Neurology. Neurosurgerv. and Psychiatry, 56, 308-310.

Stone, S. P., Halligan, P. W., \& Greenwood, R. J. (1993). The incidence of neglect phenomena and related disorders in patients with an acute right or left hemisphere stroke. Age and Ageing, 22, 46-52.

Stone, S. P., Patel, P., Greenwood, R. J., \& Halligan, P. W. (1992). Measuring visual neglect in acute stroke and predicting its recovery: The visual neglect recovery index. Journal of Neurologv. Neurosurgerv. and Psvchiatrv, 55, 431-436.

Sunderland, A., Wade, D. T., \& Langton Hewer, R. (1987). The natural history of visual neglect after stroke. Indications from two methods of assessment. International Disability Studies, 9, 55-59.

Sutton, R. L., Hovda, D. A., \& Feeney, D. M. (1989). Amphetamine accelerates recovery of locomotor function following bilateral frontal cortex ablation in cats. Behavioral Neuroscience, 103, 837-841.

Tegner, R., \& Levander, M. (1991). Through a looking glass. A new technique to demonstrate directional hypokinesia in unilateral neglect. Brain, 114, 1943-1951.

Tham, K., \& Tegner, R. (1996). The Baking Tray Task: A test of spatial neglect. Neuropsvchological Rehabilitation, 6 , 19-25.

Valenza, N., Seghier, M. L., Schwartz, S., Lazeyras, F., \& Vuilleumier, P. (2004). Tactile awareness and limb position in neglect: Functional magnetic resonance imaging. Annals of Neurology, 55, 139-143.

Vallar, G. (1997). Spatial frames of reference and somatosensory processing: A neuropsychological perspective. Philosophical Transactions of the Royal Society of London, Series B, Biological Sciences, 352, 1401-1409. 
Vallar, G., Bottini, G., Rusconi, M. L., \& Sterzi, R. (1993). Exploring somatosensory hemineglect by vestibular stimulation. Brain, 116, 71-86.

Walker-Batson, D., Curtis, S., Natarajan, R., Ford, J., Dronkers, N., Salmeron, E., Lai, J., \& Unwin, D. H. (2001). A double-blind, placebo-controlled study of the use of amphetamine in the treatment of aphasia. Stroke, 32, 2093-2098.

Walker-Batson, D., Smith, P., Curtis, S., Unwin, H., \& Greenlee, R. (1995). Amphetamine paired with physical therapy accelerates motor recovery after stroke. Further evidence. Stroke, 26, 2254-2259.

Watson, R. T., Valenstein, E., Day, A., \& Heilman, K. M. (1986). Normal tactile threshold in monkeys with neglect. Neurology, 36, 636-640.

Webster, J. S., Cottam, G., Gouvier, W. D., Blanton, P., Beissel, G. F., \& Wofford, J. (1989). Wheelchair obstacle course performance in right cerebral vascular accident victims. Journal of Clinical and Experimental Neuropsychology, 11, 295-310.

Webster, J. S., Roades, L. A., Morrill, B., Rapport, L. J., Abadee, P. S., Sowa, M. V., Dutra, R., \& Godlewski, M. C. (1995). Rightward orienting bias, wheelchair maneuvering, and fall risk. Archives of Phvsical Medicine and Rebabilitation, 76, 924-928.

Weinberg, J., Diller, L., Gordon, W. A., Gerstman, L. J., Lieberman, A., Lakin, P., Hodges, G., \& Ezrachi, O. (1977). Visual scanning training effect on reading-related tasks in acquired right brain damage. Archives of Physical Medicine and Rehabilitation, 58, 479-486.

Wiart, L., Come, A. B., Debelleix, X., Petit, H., Joseph, P. A., Mazaux, J. M., \& Barat, M. (1997). Unilateral neglect syndrome rehabilitation by trunk rotation and scanning training. Archives of Pbysical Medicine and Rehabilitation, 78, 424-429.

Wilson, B., Cockburn, J., \& Halligan, P. (1987). Behavioral inattention test. Bury St. Edmunds: Thames Valley Test Company.

Wood, S. R., Murillo, N., Bach-y-Rita, P., Leder, R. S., Marks, J. T., \& Page, S. J. (2003). Motivating, game-based stroke rehabilitation: A brief report. Topics in Stroke Rehabilitation, 10, 134-140.

Young, G. C., Collins, D., \& Hren, M. (1983). Effect of pairing scanning training with block design training in the remediation of perceptual problems in left hemiplegics. Journal of Clinical Neuropsvchology, 5, 201-212. 


\section{This article has been cited by:}

1. René M. Müri, D. Cazzoli, T. Nyffeler, T. Pflugshaupt. 2009. Visual exploration pattern in hemineglect. Psychological Research 73:2, 147-157. [CrossRef]

2. John C. Adair, Anna M. Barrett. 2008. Spatial Neglect: Clinical and Neuroscience Review. Annals of the New York Academy of Sciences 1142:1, 21-43. [CrossRef]

3. Rick Jepson, Kurt Despain, David C. Keller. 2008. Unilateral Neglect. Journal of Neuroscience Nursing 40:3, 142-149. [CrossRef]

4. ALEXANDRA LIST, JOSEPH L. BROOKS, MICHAEL ESTERMAN, ANASTASIA V. FLEVARIS, AYELET N. LANDAU, GLEN BOWMAN, VICTORIA STANTON, THOMAS M. VANVLEET, LYNN C. ROBERTSON, KRISTA SCHENDEL. 2008. Visual hemispatial neglect, re-assessed. Journal of the International Neuropsychological Society 14:02. . [CrossRef]

5. Anna M. Barrett, Charles E. Levy, Leslie J. Gonzalez Rothi. 2007. Pharmaceuticals for Poststroke and Brain Injury Rehabilitation. American Journal of Physical Medicine \& Rebabilitation 86:8, 603-604. [CrossRef]

6. Anna M. Barrett, Charles E. Levy, Leslie J. Gonzalez Rothi. 2007. Poststroke and Brain Injury Rehabilitation. American Journal of Physical Medicine \& Rebabilitation 86:7, 513-514. [CrossRef] 